\title{
P-0554 Association of serum chemerin with insulin resistance and pancreatic heta cell dysfunction in prediahetic subjects
} Bithis

\author{
KL Shams1, IA Hossain2, M Hasan3, L Ali2;
}

${ }^{1}$ Dept of Radiology \& Imaging, Bangladesh Institute of Health Sciences General Hospital, Dhaka, Bangladesh; 2Dept of Biochemistry and Cell Biology, Bangladesh University of Health Sciences, Dhaka, Bangladesh; 3Dept of Biochemistry and Molecular Biology, Rajshahi University, Rajshahi Bangladesh.

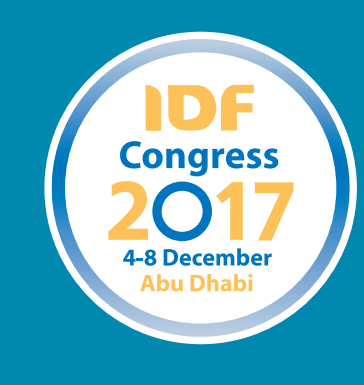

E-mail: kanizlaila75@gmail.com

\section{Background}

- Prediabetic subjects are known to be associated with insulin resistance and pancreatic beta cell dysfunction;

- The risk factors and underlying mechanism(s) of these defects vary substantially from population to population.

- The novel adipokine, chemerin has been suggested to be involved in insulin resistance in obesity and type 2 diabetes.

\section{Aim}

To investigate the association of serum chemerin with insulin secretory defect and insulin resistance among prediabetic subjects.

\section{Materials and Methods}

Study Subjects

Under an observational analytic study a group of 28 IGT (M/F 16/12; age in years, $40 \pm 9$, BMI in $\left.\mathrm{kg} / \mathrm{m}^{2} 26 \pm 3 \mathrm{M} \pm \mathrm{SD}\right), 29$ IFG $(21 / 8 ; 48 \pm 8 ; 25 \pm 5)$, 26 IFGIGT $(14 / 12 ; 46 \pm 8 ; 26 \pm 3)$ and 37 normal glucose tolerance (NGT) (19/18; $42 \pm 9 ; 24 \pm 2)$ subjects were investigated;

Inclusion criteria

- Prediabetic subjects according to the WHO Group Study criteria [1] were purposively investigated who were attending the BIHS General Hospital, Darussalam, Dhaka, Bangladesh, to check their glycemic status;

- None of the subjects had any history of using any antidiabetic agent or other medication including hormonal therapy known to affect on carbohydrate, lipid or insulin metabolism;

- They were non-smokers, non-pregnant, sedentary and had stable body weight for at least 3 months before the study and were on their normal mixed diet.

\section{Exclusion criteria}

Subjects suffering from any systemic illness like acute severe septic conditions, acute and chronic cardiac disease, hepatic, renal, acute and chronic respiratory failure, history of alcohol addiction, drugs affecting liver enzymes, cancer, stroke, type 1 diabetes, current medication and pregnant subjects was excluded from the study.

Analytical Techniques

- Fasting and postprandial serum glucose were measured by glucoseoxidase method;

- Lipid profile was measured by enzymatic-colorimetric method;

- Serum insulin and chemerin were analyzed using commercially available kits by ELISA technique;

- Insulin secretory capacity (HOMA\%B), insulin sensitivity (HOMA\%S) and Insulin resistance (HOMA-IR) were calculated from fasting serum glucose and fasting serum insulin values by homeostasis model assessment (HOMA);

- Data were analyzed by univariate and bivariate analysis as appropriate.

\begin{tabular}{|c|}
\hline Results \\
\hline 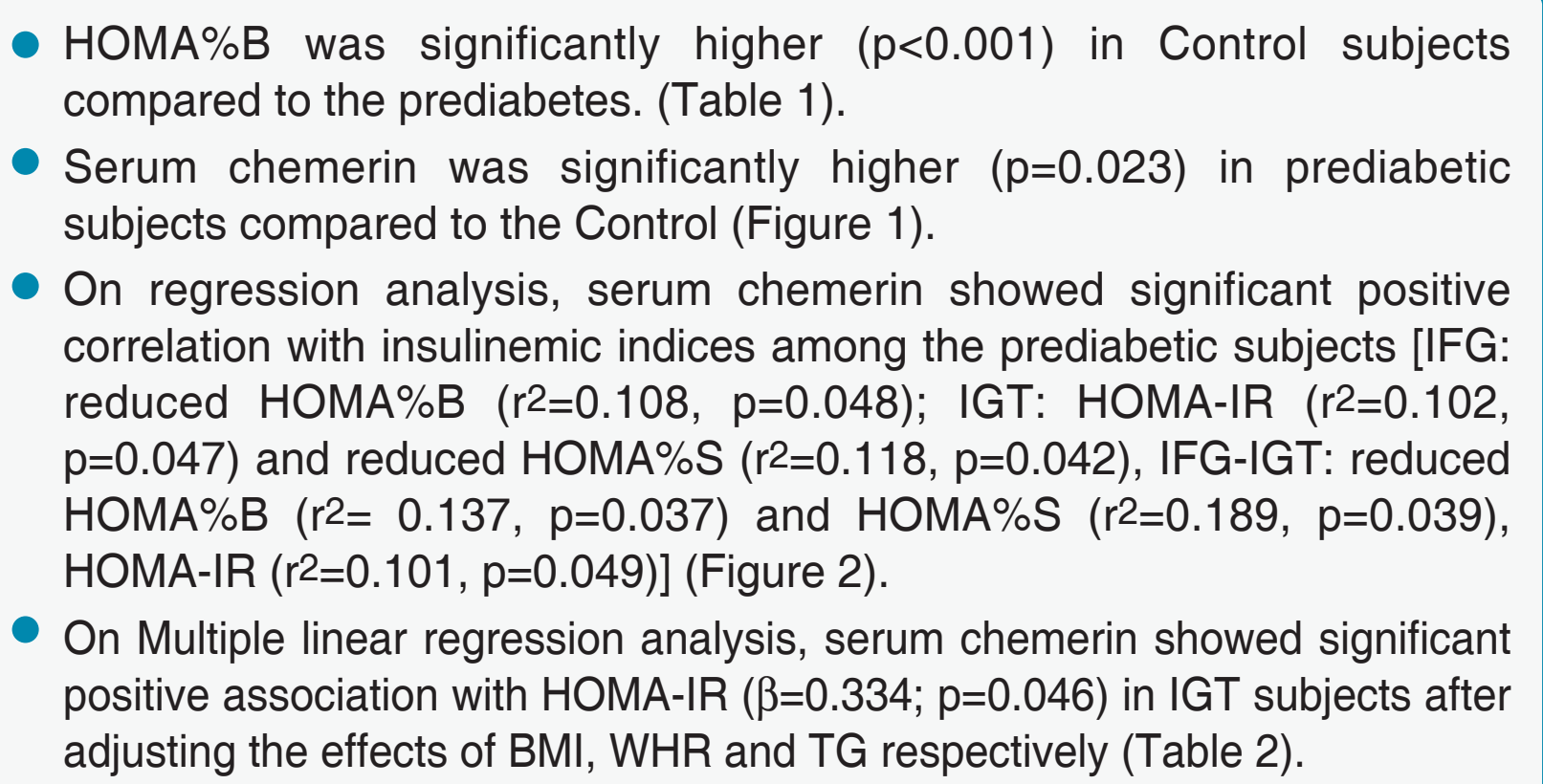 \\
\hline
\end{tabular}

Table 1: Clinical, anthropometric and biochemical characteristics of different subgroups of prediabetes

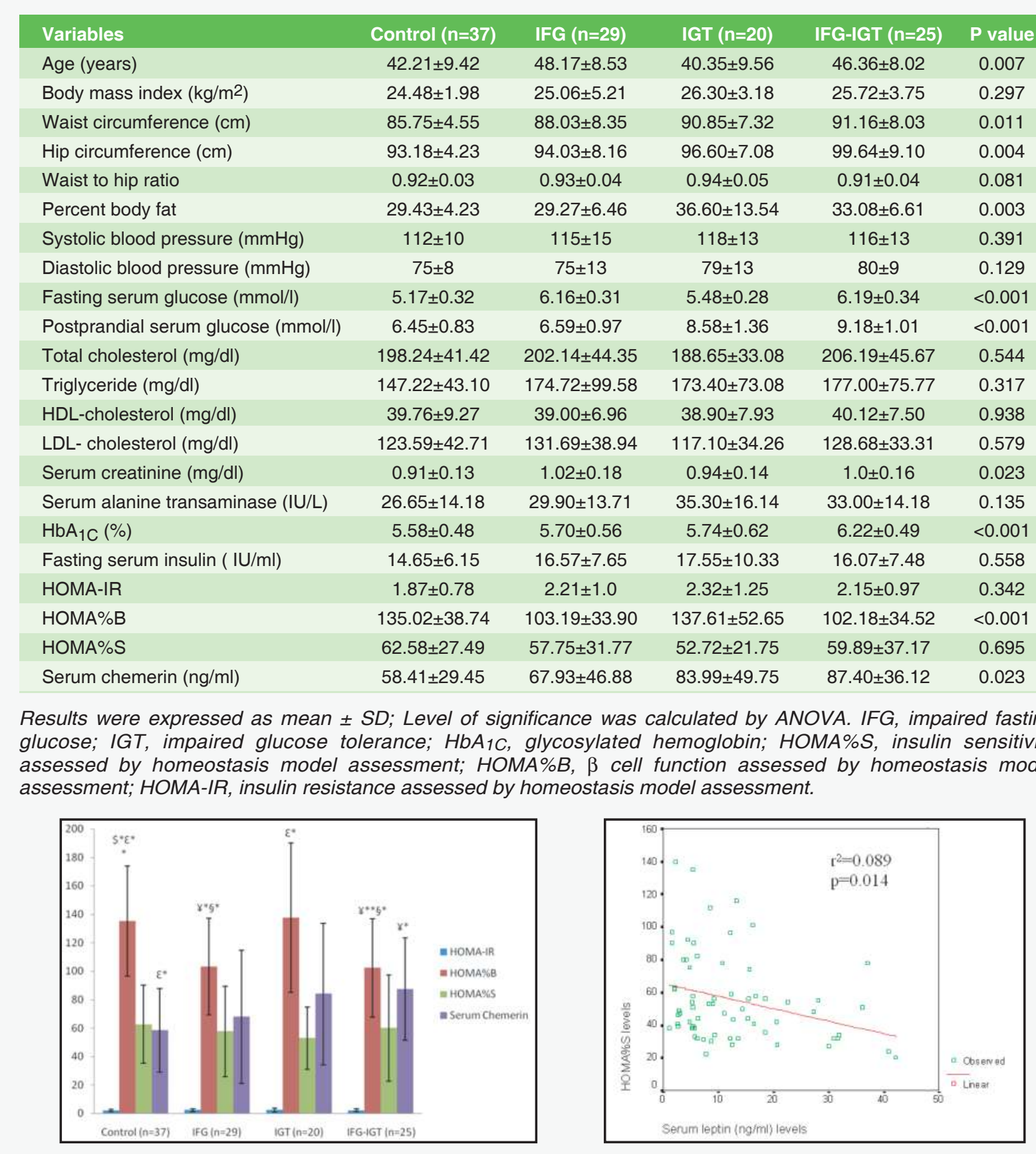

Figure 1: Insulinemic indices and serum chemerin levels in the study subjects. $\mathrm{c}<0.05^{*}, \quad \mathrm{p}=0.001^{* *}$ and $\mathrm{p}<0.001^{* *} \quad$ chemerin with HOMA-IR among
chemerin levels in the study subjects. compared with control $\left(¥^{*} \& ¥^{\star \star}\right)$, IFG $\left(\$^{*}\right)$, IGT $\left(\S^{*}\right)$ and IFG-IGT $\left(?^{*} \& ?^{* *}\right)$.

Table 2: Multiple linear regression analysis to evaluate the association of insulinemic indices with serum chemerin among the prediabetes after adjusting the effects of major confounders.

\begin{tabular}{|c|c|c|c|c|c|}
\hline \multirow{2}{*}{ Variables } & \multirow{2}{*}{$B$ value } & \multirow{2}{*}{ t value } & \multirow{2}{*}{ p value } & \multicolumn{2}{|c|}{$95 \% \mathrm{CI}$} \\
\hline & & & & Lower & Upper \\
\hline \multicolumn{6}{|c|}{ IFG subjects ( $R^{2}=0.286$ ); dependable variable: HOMA\%B } \\
\hline (Constant) & - & -0.311 & 0.759 & -380.774 & 281.831 \\
\hline Body mass index $\left(\mathrm{kg} / \mathrm{m}^{2}\right)$ & -0.272 & 1.382 & 0.182 & -1.093 & 5.384 \\
\hline Waist to hip ratio & -0.092 & 0.451 & 0.657 & -289.921 & 450.025 \\
\hline Triglyceride (mg/dl) & -0.302 & 1.493 & 0.151 & -0.040 & 0.239 \\
\hline Serum chemerin (ng/ml) & -0.149 & 0.753 & 0.460 & -0.191 & 0.406 \\
\hline \multicolumn{6}{|c|}{ IGT subjects $\left(\mathrm{R}^{2}=0.734\right)$; dependable variable: HOMA-IR } \\
\hline (Constant) & - & -4.537 & 0.000 & -21.441 & -7.735 \\
\hline Body mass index $\left(\mathrm{kg} / \mathrm{m}^{2}\right)$ & 0.318 & 2.034 & 0.060 & -0.006 & 0.257 \\
\hline Waist to hip ratio & 0.601 & 4.215 & 0.001 & 7.319 & 22.295 \\
\hline Triglyceride (mg/dl) & 0.277 & -1.887 & 0.079 & -0.010 & 0.001 \\
\hline Serum chemerin $(\mathrm{ng} / \mathrm{ml})$ & 0.334 & 1.611 & 0.046 & -0.002 & 0.014 \\
\hline
\end{tabular}

\section{Conclusions}

Serum chemerin is elevated in both IGT and IFG-IGT subjects. Although serum chemerin is associated with both insulin sensitivity and insulin secretion, however, its concentration in serum is elevated only in those prediabetic conditions which are related to insulin resistance. The underlying reason for this discrepancy needs to be investigated further.

\section{Acknowledgements}

- Diabetic Association of Bangladesh (BADAS), Dhaka, Bangladesh;

- Bangladesh Medical Research Council;

- Government of the People's Republic of Bangladesh, Ministry of Science and Technology;

- Bangladesh University of Health Sciences, Dhaka, Bangladesh.

\section{Reference}

[1] World Health Organization. Definition and Diagnosis of Diabetes Mellitus and Intermediate Hyperglycaemia: Report of a WHO/IDF Consultation. Geneva: World Health Organization. http/www.who.int/diabetes/publications/diagnosis_diabetes2006. 